\title{
Heat flux measurements for use in physiological and clothing research
}

\section{Journal Article}

\section{Author(s):}

Niedermann, R.; Psikuta, Agnes; Rossi, René M.

Publication date:

2014

Permanent link:

https://doi.org/10.3929/ethz-b-000088211

Rights / license:

In Copyright - Non-Commercial Use Permitted

Originally published in:

Biometeorology 58(6), https://doi.org/10.1007/s00484-013-0697-0 


\title{
Heat flux measurements for use in physiological and clothing research
}

\author{
R. Niedermann • A. Psikuta • R. M. Rossi
}

Received: 20 July 2012 / Revised: 22 March 2013 / Accepted: 11 June 2013 / Published online: 4 July 2013

(C) ISB 2013

\begin{abstract}
Scientists use passive heat flow meters to measure body heat exchanges with the environment. In recent years, several such sensors have been developed and concerns about their proper calibration have been addressed. However, calibration methods have differed in the geometry of the heated device as well as in the heat transfer mechanism. Therefore, a comparison of calibration methods is needed in order to understand the obtained differences in calibration lines. We chose three commercially available heat flux sensors and placed them on four different heated devices: a hot plate, double hot plate, nude cylinder and a cylinder covered with a spacer material. We found differences between the calibration line of the manufacturer and our own measurements, especially when forced convection was involved as the main heat transfer mechanism. The results showed clearly that the calibration method should be chosen according to the intended purpose of use. In addition, we recommend use a thin, light heat flux sensor with good thermal conduction in human subject studies.
\end{abstract}

Keywords Heat flux sensor $\cdot$ Human body $\cdot$ Heat balance

\section{Introduction}

Several scientists use passive heat flow meters to measure body heat exchanges with the environment (Zhang et al. 1993; Cannon and Keatinge 1960; Ferretti et al. 1989; Mcginnis and Ingram 1974; Bell et al. 1985; Basset et al. 2011;

R. Niedermann · A. Psikuta $\cdot$ R. M. Rossi $(\bowtie)$

Laboratory for Protection and Physiology, Swiss Federal

Laboratories for Materials Science and Technology (EMPA),

Lerchenfeldstrasse 5, 9014 St. Gallen, Switzerland

e-mail: rene.rossi@empa.ch

R. Niedermann

Exercise Physiology, Institute of Human Movement Sciences

and Sport, ETH Zurich, Winterthurerstrasse 190,

8057 Zurich, Switzerland
Ducharme and Kenny 2009; Tikuisis and Ducharme 1996; Mäkinen et al. 2000; Choi et al. 2003; Munir et al. 2009) The developed devices have been used mainly for indicating basal metabolic rate and blood supply to the skin (Hatfield 1950), or skin thermal resistance (Wever and Aschoff 1957). In addition, direct measurement of sensible heat flow can be compared with indirect calorimetry to overcome the disadvantages of calorimetry (Keijzer et al. 1972; Close et al. 1980).

In conclusion, the above mentioned studies vary in their attention to accurate calibration of the sensors used. Some researchers chose to use the manufacturer's calibration factors, others used developed-in-house instruments (Gin et al. 1980; Layton et al. 1983) to calibrate their sensors for a limited set of conditions. The developed-in-house instruments had different geometries (hot plate, double hot plate, and cylinder) and demonstrated distinct heat transfer mechanisms (convection, radiation, conduction). Others did not report any details at all of their calibration setup.

Danielsson (1990) raised concerns regarding the development of a sensor with accurate calibration; he presented a sensor to measure convective and radiative heat loss. In addition, he noted that the calibration technique used greatly affects both the calibration value and the measurement obtained on humans. $\mathrm{He}$ identified sensor insulation, the material under the sensor and the air flow as factors that can influence the calibration. This is in line with Frim and Ducharme (1993), who stated that the error for heat flux measurement can have different sources, including the perfusion rate of the skin, environmental conditions, thermal resistance or the thickness of the sensor. In addition, Ducharme et al. (1990) reported a mean difference of $20 \%$ when comparing the thermal constant delivered by the manufacturer with the authors' own recalibration measurements. Therefore, sensors need to be calibrated accurately and attached properly (Ducharme and Frim 1991a), and the measured value corrected accordingly (Wissler and Ketch 1982). In addition, Perl et al. (2004) recommended calibrating heat flux sensors before use, hence correcting inappropriate calibration factors given by manufacturers. 
However, the studies cited above used different calibration methods in term of the geometry of the heated devices (plate, cylinder) and the prevailing heat transfer mechanism (conduction, convection) involved. Therefore, a comparison of the influence of different geometries and heat transfer mechanism on calibration of heat flux sensors is needed. In addition, some authors suggest considering calibration of the sensor and its correction in the applied environment separately. However, it is impractical to separate these two sources of measurement error in the laboratory when using steady state conditions. Nevertheless, it can be appropriate to apply such an approach in the case of transient environmental conditions (human subject tests). The manufacturer's calibration setup is often not available to the user (internal know how), and therefore, the sensor has to be recalibrated anyway. The aim of this study was to evaluate the performance of different commercially available heat flux sensors under various heat transfer modes as reflected in the heated instruments used. Secondly, the calibration factors delivered by the manufacturers were compared with those obtained in this study. Thirdly, the utility of the chosen sensors for human physiological studies was evaluated. Based on the calibration analysis, guidelines for the calibration and use of the tested sensors are given.

\section{Methods}

\section{Heat flux sensors}

We chose three commercially available heat flux sensors based on different carrier materials into which the thermopile is embedded, but all using the same measurement principle (Seebeck effect). The sensors Omega HFS-4 (Omega Engineering, Stamford, CT), Captec (Captec Enterprise, Lille, France), and Hukseflux PU 22 T (Hukseflux Thermal Sensors, Delft, The Netherlands) were obtained directly from the respective manufacturer. The thermopile junction in all sensors was made of copper and constantan. Table 1 shows the relevant technical parameters and material properties of the heat flux sensors. To ensure good contact to the surface, the rigid sensors were fitted to the curvature of the heated cylinder.

\section{Heated devices}

For this study, we used several heated devices with different geometries and heat transfer mechanisms (Table 2). The hot plate (ISO11092:1993) and the double hot plate (ISO5085:1989) were reliable and represent the type of calibrated electronic devices usually used for textile testing. The heating power of the double hot plate and the hot plate could be maintained constant within $\pm 2 \%$ over the whole range. In addition, the temperature was maintained constant within $\pm 0.1{ }^{\circ} \mathrm{C}$ using a temperature controller including a temperature sensor ( $\mathrm{Pt} 100$ foil sensor). This is within the recommended range of standards ISO 11092 and ISO 5085. The heated plates were calibrated using an attached calibrated temperature sensor (Kelvimat, Type 4323, Burster, Germany). The heated cylinder had a diameter of $0.3 \mathrm{~m}$ and a height of $0.46 \mathrm{~m}$ and was constructed with different material layers from aluminium, polyurethane and PTFE. It consisted of three parts: the measuring part in the middle and two guards on the top and bottom ends of the cylinder. All parts were heated electrically and controlled by temperature sensors (Nickel resistance wire and Pt 100 class A foil sensors) with an accuracy of $\pm 0.2{ }^{\circ} \mathrm{C}$. The cylinder was built to simulate an adult human trunk (Zimmerli and Weder 1997). The heated cylinder was placed in five different controlled environments for calibration. An attached calibrated temperature sensor (Kelvimat, Type 4323, Burster, Germany, calibrated according to EN 60751 by Ludwig Schneider Messtechnik, Wertheim, Germany) was used as reference to calibrate the power output of the heated cylinder (Psikuta 2009; Psikuta et al. 2013). A spacer fabric was used to ensure homogenous insulation over the whole surface.

\section{Measurement procedure}

Each sensor was attached onto the different heated surfaces described in the preceding section. The sensors were fixed to the heated surface using surgical tape (Fixomull stretch, BSN Medical, Hamburg, Germany) covering the whole sensor to provide proper contact with the heated surface. The rigid round sensor from Hukselflux was warmed to adapt the sensor to the curvature of the heated cylinder prior to the experiment. In addition, the rigid Captec sensor was placed with the long side vertically on the heated cylinder to assure proper contact. All devices were placed in the same environmental conditions (ambient temperature $20.0 \pm 0.2{ }^{\circ} \mathrm{C}$, relative humidity $50 \pm 1 \%$ ). The environmental conditions with ambient temperature, relative humidity and air velocity were monitored using a thermal conditions monitoring system (ThermCondSys5500, Sensor Electronic, Gliwice, Poland). In cases where natural convection was involved (heated cylinder), the direction of the natural convection was vertical from the bottom to the top of the chamber and was measured close to the heated surface.

The measurement protocol included a three-point calibration on every heated device. We repeated each measurement three times to calculate a mean value. The different heat fluxes were obtained by adjusting the surface temperature (hot plate) or the temperature difference to the colder plate (double hot plate) for flat plates. The cylinder was set at constant heating powers of $30.4 \mathrm{~W}\left(70 \mathrm{Wm}^{-2}\right), 43.4 \mathrm{~W}(100$ $\left.\mathrm{Wm}^{-2}\right)$ and $56.4 \mathrm{~W}\left(130 \mathrm{Wm}^{-2}\right)$ to ensure highly stable heat flow. This fact and the different insulations of the heated 
Table 1 Selected technical parameters and material properties of the heat flux sensors used in this study

\begin{tabular}{llll}
\hline Parameter & Omega HFS-4 & Captec & Hukseflux PU 22 T \\
\hline Thickness $(\mathrm{mm})$ & 0.18 & 0.40 & 1.0 \\
Sensor weight $(\mathrm{g})$ & $0.3 \pm 0.1$ & $1.2 \pm 0.1$ & $3.0 \pm 0.1$ \\
Shape and dimension $(\mathrm{mm})$ & Rectangle & Rectangle & Circle \\
& $28 \times 35$ & $10 \times 40$ & 50 \\
Bending properties & Flexible & Rigid & Rigid \\
Material carrier & Polyimide film & Coopered foil & Polyurethane \\
Nominal sensitivity $\left(\mu \mathrm{V} / \mathrm{Wm}^{-2}\right)^{\mathrm{a}}$ & 1.76 & 2.34 & 40.3 \\
Thermal resistance $\left(\mathrm{m}^{2} \mathrm{~K} / \mathrm{W}\right)^{\mathrm{a}}$ & 0.004 & 0.006 & 0.004 \\
Temperature range $\left({ }^{\circ} \mathrm{C}\right)^{\mathrm{a}}$ & -200 up to +150 & -180 up to +200 & -20 up to +90 \\
Emissivity & $0.30 \pm 0.02$ & $0.98 \pm 0.01$ & $0.93 \pm 0.01$ \\
Specific heat capacity material carrier $\left(\right.$ at $\left.20^{\circ}{ }^{\circ} \mathrm{C}\right)(\mathrm{J} / \mathrm{kgK})$ & $1,090^{\mathrm{d}}$ & $385^{\mathrm{c}}$ & $1,772^{\mathrm{d}}$ \\
Thermal conductivity material carrier $\left(\right.$ at $\left.20^{\circ} \mathrm{C}\right)(\mathrm{W} / \mathrm{mK})$ & $0.045^{\mathrm{a}}$ & $0.067^{\mathrm{a}}$ & $0.750^{\mathrm{a}}$ \\
\hline
\end{tabular}

${ }^{\text {a }}$ Given by manufacturer

${ }^{\mathrm{b}}$ Measured with Lambda 19 (2,500 nm), UV/VIS/NIR spectrometer (Perkin Elmer, Norwalk, CT)

${ }^{\mathrm{c}}$ CRC handbook of chemistry and physics (Haynes 2012)

${ }^{\mathrm{d}}$ Polymer data handbook (Mark 1999)

cylinder (nude and with spacer material) resulted in different surface temperatures.

Evaluation and statistics

Based on the calibration measurements noted in Table 2, we calculated the calibration factors in the form of a slope and an intercept for a linear model as in Eq. 1.

$\mathrm{HF}_{\text {device }}=\mathrm{V}_{\text {sensor }} *$ Slope + Intercept

where $\mathrm{HF}_{\text {device }}\left(\mathrm{W} / \mathrm{m}^{-2}\right)$ is the heat flux measured by the heated devices described above and $\mathrm{V}_{\text {sensor }}(\mathrm{mV})$ is the voltage signal measured by the sensor.
In this way, an independent comparison of various calibration methods was possible, although different heat exchange regimes were involved. The calibration factor delivered by the manufacturer (in Table 1 as nominal sensitivity) corresponds to a slope and intercept at zero. We calculated the covariance of the measured heat flux $\left(\mathrm{HF}_{\text {device }}\right)$ and the voltage signal of the sensor $\left(\mathrm{V}_{\text {sensor }}\right)$ to compare the linear models. Covariance is a measure of how much two variables change together, for example in a linear model such as in our case. When the Shapiro-Wilk test resulted in a $P$-value higher than 0.05 , it was assumed that the data were distributed normally. In this case an analysis of covariance (ANCOVA) was conducted. The multiple pairwise comparisons were corrected for confidence interval adjustments with Sidak. Significance was considered as $* P<0.05, * * P<0.01$ and $* * * P<0.001$.
Table 2 Experimental settings and conditions

\begin{tabular}{llll}
\hline Heated device & Surface temperature $\left({ }^{\circ} \mathrm{C}\right)$ & $\begin{array}{l}\text { Air velocity } \\
\left(\mathrm{ms}^{-1}\right)\end{array}$ & $\begin{array}{l}\text { Prevailing heat transfer } \\
\text { mechanism }\end{array}$ \\
\hline Hot plate & $33.0 \pm 0.1$ & $1.0 \pm 0.1$ & Forced convection, radiation \\
& $35.0 \pm 0.1$ & & \\
& $37.0 \pm 0.1$ & No wind & Conduction \\
Double hot plate & $35.0 \pm 0.1$ & & Natural convection, radiation \\
& $\Delta T=1.0,2.0,3.0$ & $0.35 \pm 0.1$ & \\
Heated cylinder (nude) & $25.5 \pm 0.1$ & & Conduction, radiation \\
& $28.0 \pm 0.1$ & & \\
Heated cylinder $(+3 \mathrm{~mm}-$ & $30.3 \pm 0.1$ & $0.35 \pm 0.1$ & \\
spacer-fabric) & $34.0 \pm 0.1$ & & \\
& $37.6 \pm 0.1$ & & \\
\end{tabular}




\section{Results}

The Shapiro-Wilk test resulted in a $P$-value higher than 0.05 , and therefore, ANCOVA with additional pairwise comparison was conducted. For the Omega sensor, the pairwise comparison showed no significant difference between the four models. In addition, the models for the heated devices were not significantly different from the calibration line delivered from the manufacturer (Table 3) $(P>0.05)$. The Captec sensor showed differences in the pairwise comparison between the hot plate and the double hot plate $(P=0.009)$, heated cylinder nude $(P=0.008)$, and the heated cylinder spacer $(P=0.014)$. The other comparisons were not significantly different. Comparison of the hot plate model (Table 3) with the calibration line of the manufacturer was significantly different $(P=0.049)$. The other heated devices showed no significant differences.

The third sensor (Hukseflux) investigated in this study showed no differences when the double hot plate and cylinder nude were compared with the calibration line of the manufacturer. However, the calibration line from the manufacturer (Table 3) compared with the hot plate model $(P=0.023)$ and the heated cylinder (spacer) model $(P=0.045)$ differed significantly.

\section{Discussion}

About one-third of the linear calibration lines obtained for three different commercially available heat flux sensors on three different heated surfaces (with different heat transfer mechanisms and geometries) at three distinct heat flows were found to differ significantly from the calibration factors delivered by the manufacturers. Especially when forced convection was involved (hot plate), the obtained calibration were significantly different from the calibration factor delivered by the manufacturer in two of three sensors evaluated in this study. This confirms the need for a customized calibration before starting the measurement as proposed by Perl et al. (2004).

The Omega sensor showed no difference in the pairwise comparison for all the heated surfaces. This sensor could be used on both geometrically different heated surfaces (plate or cylinder), as well as for all tested dry heat transfer mechanisms (conduction, natural and forced convection, radiation). In addition, the comparison of every heated device with the manufacturer's calibration factor showed no significant difference (see Table 3). However, the calibration factor of the manufacturer showed a correlation coefficient from 0.56 with the measured data (Fig. 1a). Therefore, a proper calibration, especially when forced convection was involved, is required.

The Captec sensor showed a comparable performance in the pairwise comparison for the cylinder (nude, spacer) and the double hot plate, where conduction and natural convection were the main heat transfer mechanisms. The calibration factor delivered by the manufacturer also agreed with the models for the nude and dressed cylinder as well as for the double hot plate (Fig. 1b, Table 3). Conversely, we observed clear differences between hot plate and all other devices, which were probably due to the forced convection present. Therefore, the Captec sensor with the given manufacturer's calibration is most suitable for setups with prevailing conduction and natural convection,

Table 3 Slope, intercept with $\pm 1 \mathrm{SD}$ and correlation coefficient $\left(R^{2}\right)$ of the calculated linear models for all individual devices (according to Eq. 1) and the calibration value delivered by the manufacturer

\begin{tabular}{|c|c|c|c|c|c|}
\hline & Hot plate & Double hot plate & Heated cylinder (nude) & Heated cylinder (spacer fabric) & Manufacturer \\
\hline \multicolumn{6}{|l|}{ Omega } \\
\hline Slope & $809.31 \pm 15.22$ & $358.13 \pm 6.85$ & $554.02 \pm 8.54$ & $505.87 \pm 8.36$ & 564.97 \\
\hline Intercept & $-62.47 \pm 5.42$ & $2.93 \pm 0.95$ & $-3.39 \pm 1.53$ & $-8.62 \pm 1.78$ & 0 \\
\hline$R^{2}$ & 0.93 & 0.99 & 0.99 & 0.99 & 0.56 \\
\hline$P$ & 0.214 & 0.220 & 0.836 & 0.457 & - \\
\hline \multicolumn{6}{|l|}{ Captec } \\
\hline Slope & $652.43 \pm 9.83$ & $328.82 \pm 0.75$ & $405.62 \pm 1.68$ & $411.19 \pm 0.93$ & 427.35 \\
\hline Intercept & $-38.47 \pm 4.72$ & $-0.74 \pm 0.09$ & $-7.71 \pm 0.78$ & $-4.17 \pm 0.18$ & 0 \\
\hline$R^{2}$ & 0.99 & 0.99 & 0.99 & 0.99 & 0.41 \\
\hline$P$ & $0.049 *$ & 0.342 & 0.620 & 0.757 & - \\
\hline \multicolumn{6}{|l|}{ Hukseflux } \\
\hline Slope & $36.28 \pm 3.57$ & $21.89 \pm 0.04$ & $25.35 \pm 0.15$ & $59.23 \pm 1.27$ & 24.80 \\
\hline Intercept & $12.20 \pm 2.47$ & $0.45 \pm 0.10$ & $-13.45 \pm 0.56$ & $-9.45 \pm 1.85$ & 0 \\
\hline$R^{2}$ & 0.99 & 0.99 & 0.99 & 0.99 & 0.36 \\
\hline$P$ & $0.023(*)$ & 0.660 & 0.672 & $0.045(*)$ & - \\
\hline
\end{tabular}

$* P<0.05, * * P<0.01, * * * P<0.001$ (significant difference from heated devices to the calibration model delivered from the manufacturer) 
Fig. 1 Voltage vs heat flux for a Omega sensor, b Captec sensor, and $\mathbf{c}$ Hukseflux sensor a

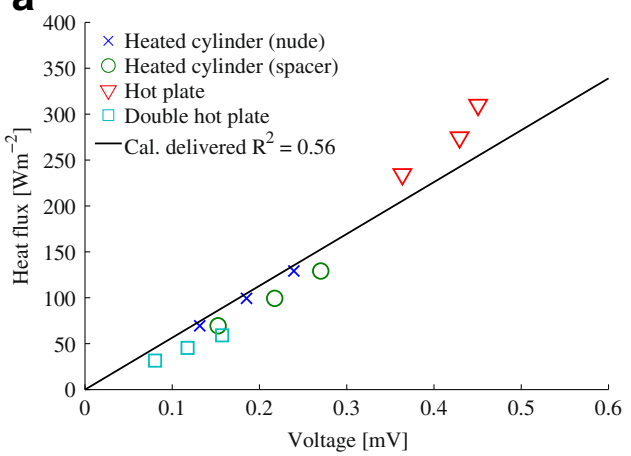

C

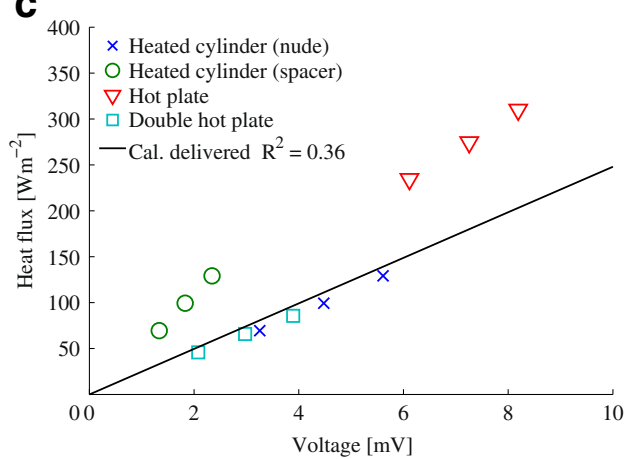

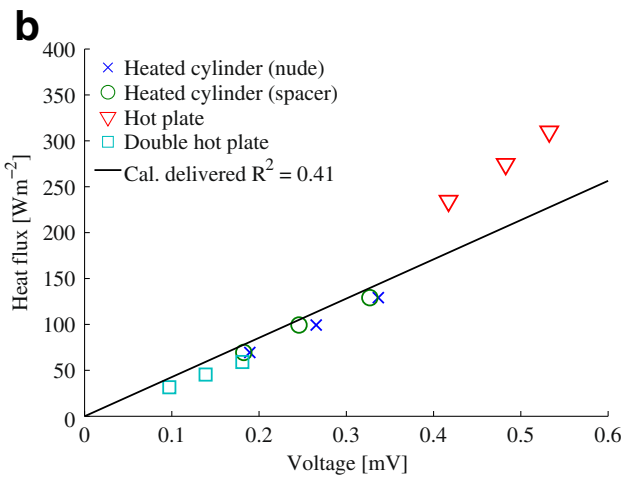

and requires additional calibration in the case of forced convection, which is similar to the case of Omega sensor.

The Hukseflux sensor showed a significantly different performance between all heated devices except for the double hot plate and the nude heated cylinder. These two measurements were also close to the calibration factor of the manufacturer (Fig. 1c). As the manufacturer used a double hot plate system for calibration as described in the delivered manual, we could confirm its calibration value. Nevertheless, the sensors showed significantly different results when forced convection and thermal radiation took place as the main heat transfer mechanism (hot plate, heated cylinder with spacer fabric).

The differences found for the Captec and Hukseflux sensor indicated that calibration is affected by the heat transfer mechanism prevailing in the calibration setup. This suggests that these heat flux sensors should be calibrated under the specific conditions of use in terms of the heat transfer mechanism involved.

The function of all the sensors used here is based on the measurement principle of the Seebeck effect. Nevertheless, the material carrier with its physical properties, such as emissivity, heat capacity as well as sensor thickness were different for every sensor (Table 1), which could influence measurement results (Ducharme et al. 1990). The small emissivity of Omega (0.33, Table 1) had no influence on the overall measurements (Fig. 1b), as thermal radiation was present as a minor heat transfer mechanism (Table 2). The sensors from Captec (black surface) and Hukseflux showed high emissivity
(0.98, 0.93 Table 1) and are more appropriate for human subject testing protocols using thermal radiation sources than Omega, as their emissivity is nearer to skin emissivity (about 0.98). The thermal properties of the carrier material of the sensors (specific heat capacity, thermal conductivity, Table 1) were different. However, the values are not far from each other when compared with the heat capacity of the skin. Therefore, the thermal properties of the chosen sensors cannot explain the differences found in calibration. The different thickness of the sensor may have an influence on the measured heat loss. On a thicker sensor, more turbulence occurs, and therefore heat loss by convection might be higher. The size and bending properties differ for each sensor. The Omega sensor was built on a flexible foil that enables a good contact to different surfaces (plate, cylinder) and showed no difference between cylinder and flat plate. On the contrary, the rigid sensors from Captec and Hukseflux showed significant differences between the flat plate and the cylinder. This can most probably be explained by the different contact areas, which influences the result measured on a flat or curved surface (the diameter of heated cylinder was $0.30 \mathrm{~m}$ ). Since the size of the Captec sensor and the curvature of the heated cylinder were small, the incomplete contact is less of a problem compared to the larger sensor of Hukseflux. Therefore, the sensor of Huskeflux had to be bent to fit to the curvature of the cylinder to ensure good thermal contact.

Not only the physical properties of the heat flux sensor but also vasodilated skin can lead to an underestimation of the measured result (Ducharme and Frim 1991b). In vasoconstricted 
skin, this underestimation is much lower and the physical properties of the sensor again become important. This additional factor has to be considered when planning a human experiment.

Although the sensors used in this study were developed for a wide range of applications, they are suitable for human physiological studies due to their small size, light weight, flexibility, and sensitivity, which is suitable for the range and accuracy required in such studies (Table 1). The measurement accuracy for the relatively small heat flux range observed in humans located roughly in the middle of the application range of the sensor could be burdened with errors depending on the number and distribution of calibration points over the measurement range. This fact again confirms the need for calibration if a high accuracy in the small portion of the measurement range is required. Moreover, the influence of vasodilation and vasoconstriction of the human skin on the sensor reading has not been evaluated in this study.

\section{Conclusion}

The evaluation of three different heat flux sensors in measurement settings involving different heat transport mechanisms (conduction, natural and forced convection, and radiation) showed that the calibration factors provided by the manufacturer often disagreed with those obtained in our measurements. Furthermore, the sensors responded differently to the calibration setups with the various heat transport mechanism involved and, therefore, one overall model for a calibration value is not sufficient in every case. Therefore, a proper calibration corresponding to the intended purpose of use is required, including the range of heat flux used and adequate air velocity when forced convection is involved. This means that the choice of the sensor depends on the experimental protocol, which includes the chosen environment and clothing. These factors must be considered when measurement results have to be corrected due to underestimation.

It is also important to report details of the calibration procedure in any publication describing heat flux measurements. Similarly, the manufacturer's calibration factors, with a description of the calibration method used should be provided at the time of purchase of the sensors in order to benefit most from these sensors. As the heat flux from the human surface is typically very small, factors influencing the sensor reading, such as thermal resistance, weight, or flexibility of the carrier material have to be considered. We recommend use of a thin, light sensor with good thermal heat flux conductance for human subject studies. However, in this work the sensors were tested under steady-state conditions, and therefore, more research is needed to evaluate these sensors in transient conditions.
Acknowledgments This study was supported financially partially by the EU project PROSPIE (FP7-NMP-229042). In addition, we thank Rolf Stämpfli and Martin Camenzind for their constructive comments on the measurement setup.

\section{References}

Basset FA, Cahill F, Handrigan G, Ducharme MB, Cheung SS (2011) The effect of lower body cooling on the changes in three core temperature indices. Physiol Meas 32:385-394

Bell PY, Padbury EH, Hayes PA (1985) Optimal siting of heat flux transducers for the assessment of body heat loss when immersed in water. Undersea Biomed Res 12:465-483

Cannon P, Keatinge WR (1960) The metabolic rate and heat loss of fat and thin men in heat balance in cold and warm water. J Physiol 154:329-344

Choi JK, Lee HS, Park YS, Shiraki K (2003) Effect of uniform and nonuniform skin temperature on thermal exchanges in water in humans. Int J Biometeorol 47:80-86

Close WH, Dauncey MJ, Ingram DL (1980) Heat loss from humans measured with a direct calorimeter and heat-flow meters. Br J Nutr 43:87-93

Danielsson U (1990) Convective heat transfer measured directly with a heat flux sensor. J Appl Physiol 68:1275-1281

Ducharme MB, Frim J (1991a) Methodoloy for calibration and use of heat flux transducers. Institute of Environmental Medicine. Downsview, Ontario

Ducharme MB, Frim J (1991b) Methodoloy for calibration and use of heat flux transducers Institute of Environmental Medicine, Downsview, Ontario

Ducharme MB, Kenny GP (2009) A calorimetric validation of evaporative and dry heat losses measured with heat flow transducers. Paper presented at the 13th International Conference on Environmental Ergonomics, Boston

Ducharme MB, Frim J, Tikuisis P (1990) Errors in heat-flux measurements due to the thermal resistance of heat-flux disks. J Appl Physiol 69:776-784

Ferretti G, Veicsteinas A, Rennie DW (1989) Conductive and convective heat flows of exercising humans in cold water. J Appl Physiol 67:2473-2480

Frim J, Ducharme MB (1993) Heat-flux transducer measurement error-a simplified view. J Appl Physiol 74:2040-2044

Gin AR, Hayward MG, Keatinge WR (1980) Method for measuring regional heat-losses in man. J Appl Physiol 49:533-535

Hatfield HS (1950) A heat flow meter. J Physiol 111:10-11

Haynes WM (ed) (2012) CRC handbook of chemistry and physics. Taylor and Francis, Boca Raton

ISO11092:1993 (1993) Sweating guarded-hotplate test. International Standards Organisation, Geneva

ISO5085:1989 (1989) Determination of thermal resistance. Part 1: Low thermal resistance. International Standards Organisation, Geneva

Keijzer A, Kluver BDR, Buist M, Woerlee M (1972) Direct measurement of sensible heat-transfer between man and his environment. J Appl Physiol 33:677-680

Layton RP, Mints WH Jr, Annis JF, Rack MJ, Webb P (1983) Calorimetry with heat flux transducers: comparison with a suit calorimeter. J Appl Physiol 54:1361-1367

Mäkinen T, Gavhed D, Holmer I, Rintamaki H (2000) Thermal responses to cold wind of thermoneutral and cooled subjects. Eur J Appl Physiol 81:397-402

Mark JE (ed) (1999) Polymer data handbook. Oxford University Press, New York 
Mcginnis SM, Ingram DL (1974) Use of heat-flow meters to estimate rate of heat loss from animals. J Appl Physiol 37:443-446

Munir A, Takada S, Matsushita T (2009) Re-evaluation of Stolwijk's 25-node human thermal model under thermal-transient conditions: predictions of skin temperature in low-activity conditions. Build Environ 44(9):1777-1787

Perl T, Brauer A, Weyland W, Braun U (2004) Application of heat flux transducers to determine perioperative heat exchange. Thermochim Acta 422:35-40

Psikuta A (2009) Development of an 'artificial human' for clothing research, $\mathrm{PhD}$ thesis, De Montfort University, Leicester

Psikuta A, Niedermann R, Rossi, RM (2013) Effect of ambient temperature and attachment method on surface temperature measurements. Int J Biometeorol (in press)
Tikuisis P, Ducharme MB (1996) The effect of postural changes on body temperatures and heat balance. Eur J Appl Physiol 72:451459

Wever R, Aschoff J (1957) Die Wärmedurchgangszahl als Durchblutungsmass am Menschen Pflugers. Arch Eur J Physiol 264:272279

Wissler EH, Ketch RB (1982) Errors involved in using thermal flux transducers under various conditions. Undersea Biomed Res 9:213-231

Zhang XZ, Dai ZZ, Zhou GH (1993) Application of the heat-flux meter in physiological-studies. J Therm Biol 18:473-476

Zimmerli T, Weder MS (1997) Protection and comfort-a sweating torso for the simultaneous measurement of protective and comfort properties of PPE. Am Soc Test Mater 1273:271-280 